\title{
Age, Gender, and Bone Lamellae Elastic Moduli
}

\author{
C. E. Hoffler, K. E. Moore, K. Kozloff, *P. K. Zysset, and S. A. Goldstein \\ Orthopaedic Research Laboratories, Department of Surgery, University of Michigan, Ann Arbor, Michigan, U.S.A.; \\ and ${ }^{*}$ Laboratory of Applied Mechanics and Reliability Analysis, Department of Mechanical Engineering, \\ Swiss Federal Institute of Technology, Lausanne, Switzerland
}

\begin{abstract}
Summary: To enhance preventative and therapeutic strategies for metabolic bone diseases and bone fragility disorders, we began to explore the physical properties of bone tissue at the cellular level. Proximal femurs were harvested from 27 cadavera ( 16 male and 11 female) for in vitro measurement of the mechanical properties. We measured the variations in lamellar-level elastic modulus and hardness in human bone as a function of age and gender to identify microstructural properties responsible for age and gender-related reductions in the mechanical integrity. The lateral femoral necks were examined, and age, gender, height, body mass. and body mass index were not found to correlate with lamellar-level elastic modulus or hardness. This result was consistent for osteonal, interstitial, and trabecular tissue. These data suggest that increased bone mass maintenance, known to occur in heavier individuals, is not accompanied by increases in the lamellar-level elastic modulus or hardness. The independence of elastic modulus and hardness from age and gender suggests that age and gender-related decreases in mechanical integrity do not involve alterations in elastic modulus or hardness of the extracellular matrix. Lamellar-level ultimate, fatigue, and fracture toughness properties should also be investigated. Other factors, such as tissue mass and organization, may also contribute to age and genderrelated decreases in the mechanical integrity.
\end{abstract}

To enhance preventative and therapeutic strategies for metabolic bone diseases and bone fragility disorders, we began to explore the mechanical properties of bone at the cellular level. Quantifying the properties of bone extracellular matrix is essential to defining the ctiology and pathogenesis of several skeletal maladies, such as osteoporosis, osteomalacia, osteogenesis imperfecta, and age or gender-related increases in bone fragility. Numerous investigators have explored the influence of macroscopic bone architecture and material properties on failure; however, they have been unable to identify specific mechanisms that lead to increases in age and genderrelated fragility $(9,13,22)$.

Beginning with large volumes of bone tissue, many researchers have characterized age-related reductions in trabecular $(31,39,43,44)$ and cortical $(10,16,19,25$, $30,32,41-43$ ) bone material properties and found that more microscopic properties, such as mineral content, failed to consistently explain declining ultimate properties of cortical bone (30) or trabecular bone strength (44) with age. These results suggest that other factors, such as trabecular architecture, lamellar-level mechanical properties, or ultrastructural organization,

Received March 31, 1999; acceptcd September 9, 1999.

Address correspondence and reprint requests to S. A. Goldstein at Orthopaedic Research Laboratories, Department of Surgery, University of Michigan, G-0161 400 North Ingalls Street, Ann Arbor, MI 48109-0486, U.S.A. E-mail: stevegld@umich.edu may also play an important role in age-related decreases in whole-bone mechanical properties.

Superimposed on these lexicons of age-dependent measurements are substantial data detailing gender variations in mechanical, architectural, and matrix characteristics $(7,8,10,20,30,32,33,38,44)$. For example, cortical bone porosity $(30,33)$ and microcrack density (38) have been demonstrated to increase more rapidly in women with age. These data suggest that age-dependent alterations in lamellar-level mechanical properties may be distinct in men and women.

Recently, nanoindentation has been used to measure lamellar-level bone elastic properties $(24,28,35$, $36,47)$. To our knowledge, the lamellar-level elastic properties of fresh human bone as a function of age and gender have not been examined. We hypothesized that the constitutive properties of bone matrix at the lamellar level may decline with age and differ between genders. The purpose of our study was to measure variations in the lamellar-level elastic modulus in human bone as a function of age and gender to identify microstructural properties that may be responsible for age and gender-related reductions in mechanical integrity.

\section{MATERIALS AND METHODS}

All of the specimens used in the present study were obtained through the University of Michigan Anatomical Donations Program. Cadavera were fresh frozen and screened for arthroplasty, 


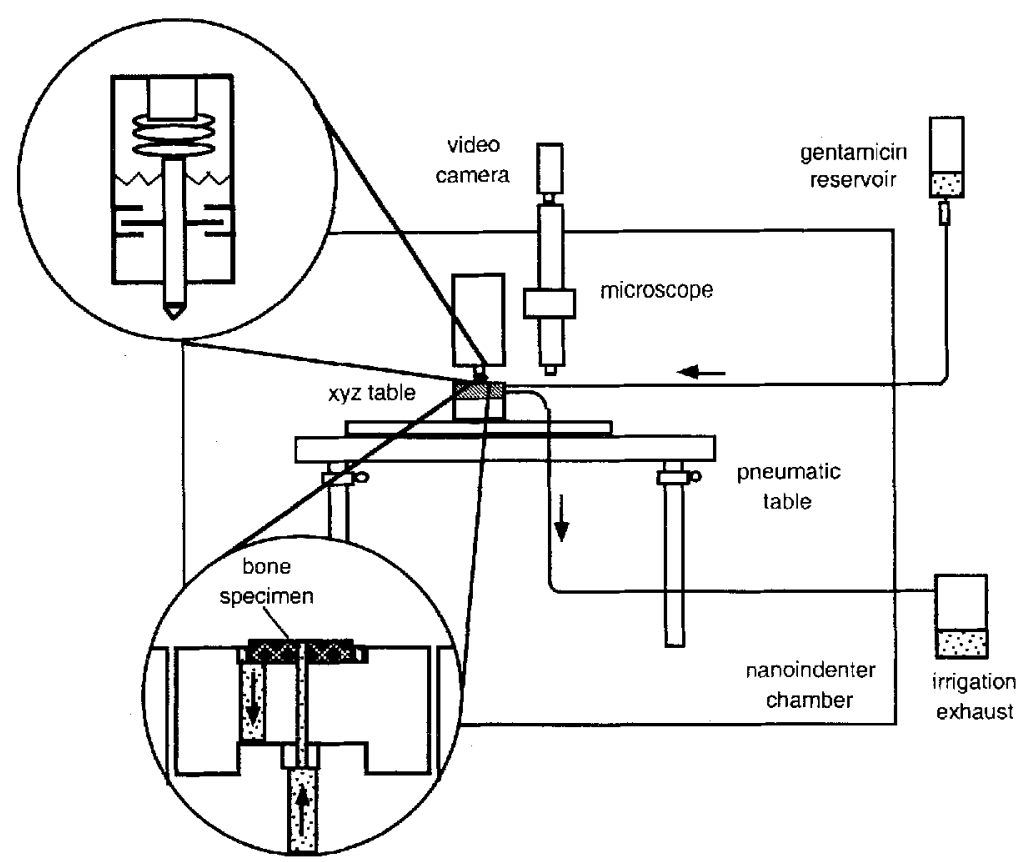

FIG. 1. Schematic diagram of the NanoIndenter II and the custom irrigation system.

osteosarcoma, paralysis, and metabolic bone disorders. The bone specimens were obtained from 16 male cadavera, $40-85$ years old at death, and 11 Cernale cadavcra, 27-93 years old at death. Given. the prevalence of fragility fractures of the proximal femur, femoral neck tissue was selected as an area with properties that might be of clinical interest $(13,29)$.

Two separate comparisons were made. Agc and gender effects were evaluated in the complete sample of 27 cadavcra and in an age-matched subset of 19 cadavera (11 male and eight fomale [postmenopausal]) at least 60 years old.

The femoral neck was scctioned with an irrigated diamond band saw (Exakt Instruments, Oklahoma City, OK, U.S.A.) transverse to its anatomical axis, bcginning proximal to the greater trochanter. Samples, $1 \mathrm{~cm}^{2}$ each, were removed from the lateral portion of the section with a scalpel. The samples contained a trabecular interior bordered on one edge by a compact bone cortex.

All of the sections werc $3 \mathrm{~mm}$ thick, less the thickness of the blade $(200 \mu \mathrm{m})$. The tissuc samples were embedded in a mildly exothermic epoxy (PL-1; Photoclastic Division, Measurements Group, Raleigh, NC, U.S.A.), sccured to polycarbonate platens, and rehydrated. The epoxy filled pores between trabeculae but did not penetrate lamellar tissue. The specimens were surfacepolished with progressive grades of $\mathrm{SiC}$ paper, linished with a $0.25-\mu \mathrm{m}$ diamond slurry, and washed in an ultrasonic water bath for 15 minutes.

The NanoIndenter II system (Nano Instruments, Oak Ridgc, TN, U.S.A.) was used to measure the elastic modulus of bone lamellae. Nanoindentation is similar to traditional hardness-testing but incorporates depth-sensing technology to measure elastic modulus. In nanoindentation, a diamond probe is pressed into a test matcrial and retracted, leaving a permanent impression. Load and depth are recorded with $0.3-\mu \mathrm{N}$ and $0.16-\mathrm{nm}$ resolutions, respectively. Modifying the Sneddon solution (40) to indentation of an elastic half-space with a rigid, axisymmetric indenter, Doerner and Nix (18) modeled nanoindentation as a deformable cylinder indenting an elastic half-space. 'They related the initial unloading stiffness to elastic modulus under the following assumptions: the Poisson ratio is known, the material is isotropically elastic with rate-independent plasticity, and contact is maintained during initial unloading. Oliver and Pharr (34) refined this approach to ac- commodate nonlinear unloading behavior and incorporated King's modifications (27) for indenters of different cross sections. The initial unloading stiffness, $S$, is related to the elastic modulus as follows:

$$
S=d P / d h=2 \beta E_{r} \sqrt{A_{t} / \pi}
$$

where $P$ is the load, $h$ is the depth, and $d P / d h$ is the initial slope during unloading of the force-displacement curve. $\beta$ is an empirical factor to distinguish different indentor shapes, and $A_{i}$ is the projected area of contact. $E_{r}$ is the reduced modulus, and it accounts for the finite stiffness of the indenter:

$$
1 / E_{r}=\left(1-v_{b}^{2}\right) / E_{b}+\left(1-v_{i}^{2}\right) / E_{i}
$$

$E_{b}$ and $v_{b}$ are the elastic modulus and the Poisson ratio for bone,

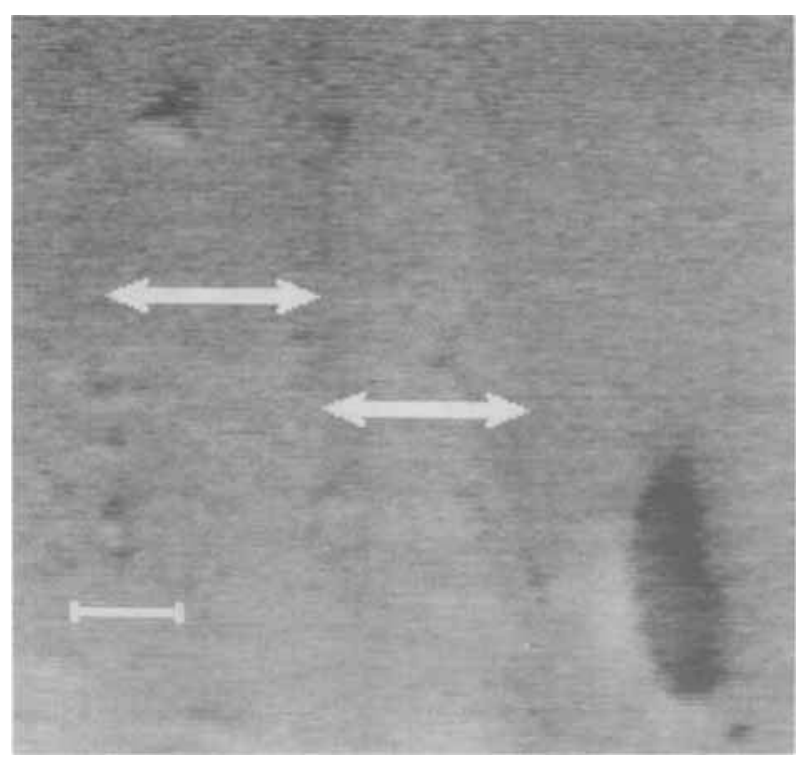

FIG. 2. A 500-nm-deep indentation adjacent to an ostcocyte cell body (lacuna) in interstitial tissue. The thickness of each lamella is indicated by a double-headed arrow. Scale bar $=5 \mu \mathrm{m}$. 


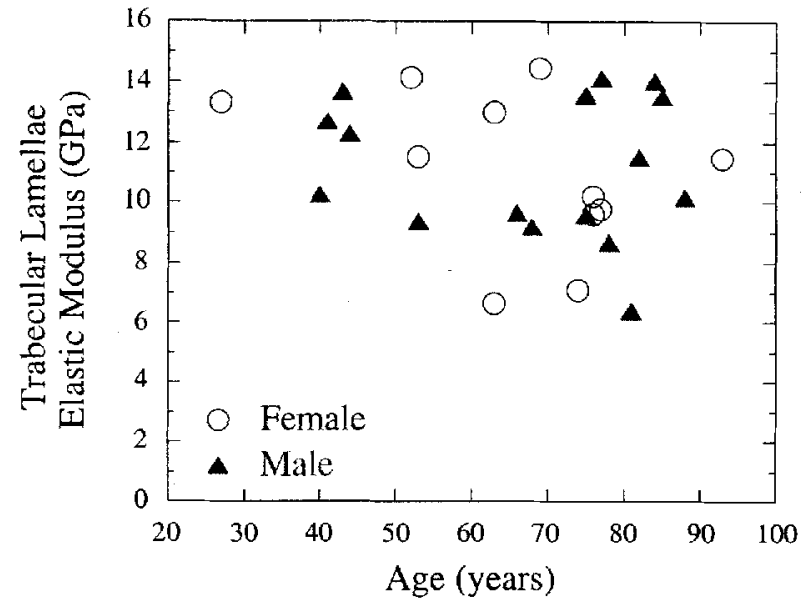

FIG. 3. Graph showing the independence of lamellar-level elastic modulus of trabecular tissue from age and gender.

respectively. $E_{i}$ and $v_{i}$ are the same quantities for the indenter. The projectcd arca of contact is determined by the contact depth and is calculated on the basis of the area-to-depth function of the indenter. Given that indenter geometry can vary substantially from manufacturer to manufacturcr, the cross-sectional area as a function of depth is derived empirically for each indenter. The experimental model for nanoindentation and the calibration of the indenter shape have been carefully validated for aluminum, quartz, sapphire, fused silica, soda lime glass, and tungsten (34).

Hardness, $H$, is defined as the maximum force, $P_{m n x}$, divided by the projected area of contact and may also be calculated from the load-displacement data and the area-to-depth function:

$$
H=P_{\text {max }} / A_{c}
$$

The NanoIndenter II is equipped with a pyramidal Berkovich diamond indenter, a microscope, and a coordinate table, all of which are located on a vibration-isolation platform within a protective cabinet. Load and depth are controlled with an inductive load-cell and a capacitive displacement gauge, respectively. Cus$10 \mathrm{~m}$ irrigation was designed to maintain tissue moisture with an antibacterial solution of $0.5 \mu \mathrm{g} / \mathrm{ml}$ gentamicin (Life Technologies, Grand Island, NY, U.S.A.) (Fig. 1).

Using a light microscope, wo selected locations for the indentations on the basis of the histological morphology of the microstructures. Femoral neck tissue was classified into osteonal, intcrstitial, and trabecular microstructures. Within a single specimen, nine regions of each microstructurc present were tested. At each region of interest, a $30-\mu \mathrm{m}^{2}$ array of four indentations was made (for a total of 108 indentations per spccimen). Indentation was performed al $10 \mathrm{~nm} / \mathrm{sec}$, to a maximum depth of $500 \mathrm{~nm}$. Testing parameters were selected to be consistent with those of a previous study that yielded reproducible data (47). As described earlier, the lamellar-level elastic modulus was then calculated from the unloading segment of the force-displacement curve assuming a Poisson ratio of 0.3 . Recent results indicate that trabecular tissuc may have an isotropic Poisson ratio of 0.25 (46) and that bone elastic modulus varies only within $10 \%$, between Poisson ratios of 0.2 and 0.4 , when measured with nanoindentation (47). Lamellar tissue hardness was also determined.

We subsequently examined the ability of body mass, hcight, and body mass index to predict lamellar-level elastic modulus and hardness. From the original sample of 27 cadavera, three subsets were isolated on the basis of availability of weight and height data. A subset of 21 cadavcra (12 male and nine female) was used for the mass study, a subset of 19 cadavera (10 male and nine female) was used for the height study, and a subset of 18 cadavera (nine male and nine female) with available weight and height data was used for the height and body mass index study.

Hardness was transformed to logarithms before analysis because the distribution of hardness was skewed to the right. For each cadaver, the mean values for elastic modulus and transformed hardness were calculated for each microstructure. For each microstructure, these values were then used as the observations in a general linear regression model. We first fit elastic modulus and transformed hardness for all of the cadavera to a model containing age, age ${ }^{2}$, and gender. We then restricted the data to only cadavera that were at least 60 years old at death. Next, we fit the data for all of the cadavera using a model containing weight and gender and a second model containing body mass index and height. To test whether elastic modulus and hardness differ between microstructures, we fit the data for all three microstructures by a mixed-model analysis of variance in which microstructure was a fixed effect (repeated for each cadaver) and donor was a random effect. $P$ values of less than 0.05 were considered significant.

\section{RESULTS}

Of 2,916 possible indentations, 175 were excluded because of equipment failure or fluid saturating the testing surface. An additional 53 measurements were not included because the data were recorded at depths more than $10 \%$ away from the 500 -nm target depth (Fig. 2). Lastly, 24 statistical outliers were eliminated because they differed by more than $20 \%$ from the next closest datum point. Thus, the final data set consisted of 2,664 observations.

For both elastic modulus and transformed hardness, the models fitted with use of age and gender were not significant for either the entire sample or the subset of cadavera at least 60 years old. The models fitted with use of weight and gender, height, or body mass index were not significant either. Correlations were absent for all of the microstructures. For elastic modulus, the variance of regions within a specimen was approximately four times larger than the variance of individual observations. The variance of donors exceeded that of regions within a sample by a similar

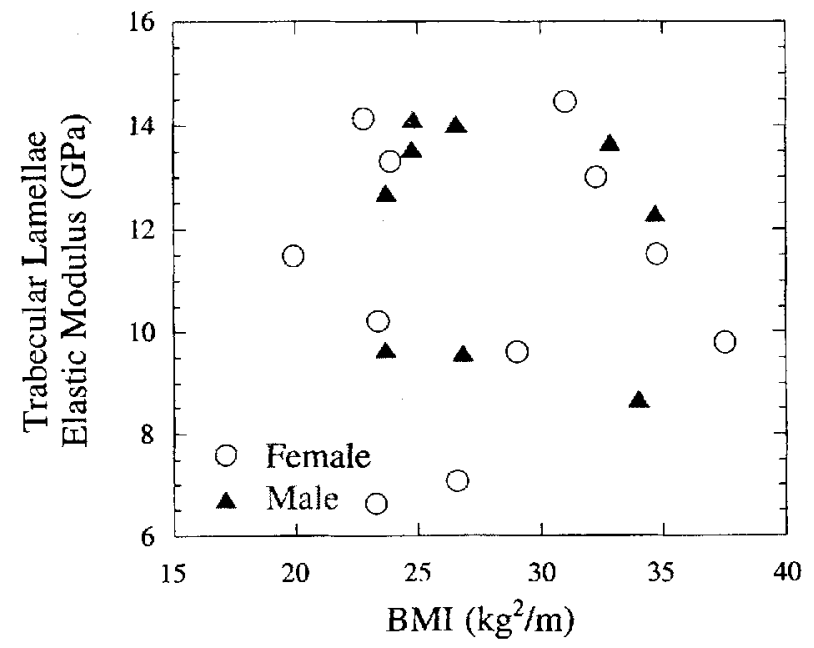

FIG. 4. Graph showing the independence of lamellar-level elastic modulus of trabecular tissue from body mass index (BMI). 


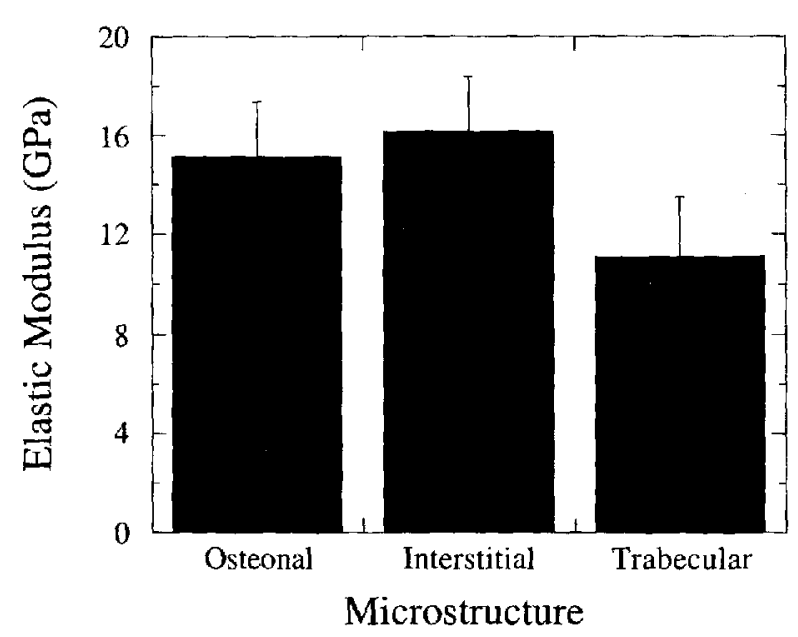

FIG. 5. Graph showing the microstructural differences in elastic modulus.

margin. The hardness variances differed by similar factors. The lamellar-level properties of trabecular tissue were found to be independent of age and gender (Fig. 3). The elastic modulus and body mass index were also independent (Fig. 4). The data do not indicate changes in lamellar-level elastic modulus or hardness as a function of age, gender, weight, height, or body mass index.

In contrast, the lamellar-level elastic modulus and hardness of bone did depend on microstructure. Both parameters differed significantly among all microstructures ( $p<0.05$ for all comparisons) (Fig. 5). Interstitial tissue was determined to have a greater elastic modulus $(16.13 \pm 2.2 \mathrm{GPa}[$ mean $\pm \mathrm{SD}])$ and hardness $(0.55 \pm 0.07 \mathrm{GPa})$ than osteonal tissue $(15.11 \pm$ 2.2 and $0.51 \pm 0.10 \mathrm{GPa}$, respectively), which had greater properties still than trabecular tissue $(11.10 \pm$ 2.4 and $0.44 \pm 0.14 \mathrm{GPa}$, respectively).

\section{DISCUSSION}

The most striking results from the present study are that lamellar-level elastic modulus and hardness are independent of age and gender in the lateral femoral neck. Because no correlation was found, we sought additional parameters to explain the variations in lamellar mechanical properties between cadavera. Bone mass has been shown to correlate with body weight, percentage of ideal body weight, and body mass index (17), indicating a possible role for functional strains in bone mass regulation (37). Our data demonstrate that neither of these body mass or height factors is an effective predictor of lamellar elastic modulus or hardness. Furthermore, the results of the current study suggest that increased bone mass maintenance, known to occur in heavier individuals (17), is not accompanied by increases in the elastic modulus or hardness of the extracellular matrix.

More than three decades ago, Weaver published an extensive study detailing the microhardness of moist human bone lamellae and its variation with age and gender (43). He tested interstitial tissue of the fibula on surfaces normal to the anatomical axis and found bone microhardness to be independent of age and gender in skeletally mature adults. Our findings confirm those of Weaver and extend them to osteonal and trabecular microstructures, elastic modulus, and, most importantly, to a region with a higher incidence of fracture. Interestingly, Weaver also found very little intersubject variation, which is in marked contrast to the current results. This discrepancy may result from Weaver's use of the maximum triad of values selected from 10 total observations on each tissue specimen.

On the basis of backscatter electron imaging, Crofts et al. (14) found older cadavera (60-71 years old at death) to have a lower equivalent ash content in the femoral neck than younger cadavera (17-35 years old at death). Alternatively, Aerssens et al. (1) found calcium content in the femoral neck to increase with age. Neither finding supports the independence of lamellar-level mechanical properties from age, even though relationships between hardness and various mineral measures have been reported $(11,23,43)$. Clearly, a more complete cross-sectional study integrating biochemical and mechanical measures is necessary. The role of mineral constituents in dictating variations in the lamellar-level elastic modulus and hardness with age remains unknown.

Increases in femoral neck width have been demonstrated to compensate for decreases in bone mineral density and cross-sectional area in older men (7). However, a similar compensation does not occur in postmenopausal women (8). The results of the current study suggest that these architectural adaptations in men are not accompanied by changes in the modulus or hardness of bone in the extracellular matrix. In addition, the absence of structural adaptation in postmenopausal women and the similarity of lamellar elastic modulus and hardness in men and women suggest that bone organization may contribute to increases in gender-related fragility. Other lamellarlevel mechanical properties may also play a role.

Microstructurally, our study demonstrates that the elastic modulus values for interstitial tissue exceed those for osteonal tissue and that the values for trabecular tissue are lower than both. Rho et al. (35) reported similar results for dry tibial bone. These mechanical differences may reflect mineralization discrepancies due to tissue age. The results are consistent with interstitial tissue being older and more mineralized than osteonal tissue and trabecular tissue being lurned over more frequently, possibly for mineral homeostasis (26). Collagen fiber orientations vary in both cortical and trabecular bone measurements. Specifically, osteonal bone measurements represent a random mixture of ostcons with collagen fiber prefer- 
entially oriented longitudinally, transversely, or alternating between the two alignments (2-6). Because of the complex architecture of trabecular tissue, measurements in trabecular lamellae were also made at different orientations with regard to collagen fiber orientation. The effect that different distributions of collagen fiber orientation have within microstructural groups is unknown.

Although our results detail the relationship between age and lamellar elastic modulus and hardness, the implications of this investigation should be tempered in light of the sample size of our data. Also, we selected cadavera without femoral neck fractures that may not represent individuals who will subsequently experience fracture. In addition, we restricted our attention to the femoral neck, recognizing that considerable variation exists in mechanical properties and aging trends in different anatomical locations $(12,21,45)$. Our study quantified lamellar-level elastic modulus and hardness only. The principal lamellarlevel material properties responsible for prescribing whole-bone mechanical integrity are unknown. Ultimate, fatigue, and fracture toughness properties of the extracellular matrix may also be important determinants of the mechanical integrity of whole bone.

Despite these limitations, the independence of lamellar elastic modulus and hardness from age and gender suggests that declines in lamellar-level mechanical properties may not be responsible for age and gender-related decreases in the mechanical integrity of whole bone. There is an absence of correlation for both elastic modulus and hardness, which are measures of elastic and yield properties (15), respectively. Lamellar-level ultimate, fatigue, and fracture toughness properties should also be investigated. Additionally, other factors, such as tissue mass and organization, may contribute more substantially to age and gender-related decreases in mechanical integrity than extracellular matrix properties.

Acknowledgment: The authors would like to recognize Professor M. Brown and W. Pan for statistical consultations and M. Dillon for technical assistance. This work was supported by National Institutes of Health Grant AR 34399.

\section{REFERENCES}

1. Aerssens J, Boonen S, Joly J, Dequeker J: Variations in trabecular bone composition with anatomical site and age: potential implications for bone quality assessment. $J$ Endocrinol 155:411-421, 1997

2. Ascenzi $\mathrm{A}$, Bonucci $\mathrm{E}$ : The tensile properties of single osteons. Anat Rec 158:375-386, 1967

3. Ascenzi A, Bonucci $\mathrm{E}$ : The compressive properties of single osteons. Anat Rec 161:377-391, 1968

4. Ascenzi A, Bonucci E: The shearing properties of single osteons. Anat Rec 172:499-510, 1972

5. Ascenzi A, Benvenuti A, Bonucci B: The tensile properties of single osteonic lamellae: technical problems and preliminary results. $J$ Biomech 15:29-37, 1982

6. Ascenzi A, Baschieri P, Benvenuti A: The bending properties of single osteons. J Biomech 23:763-771, 1990

7. Beck TJ, Ruff CB, Scott WW Jr, Plato CC, Tobin JD, Quan $\mathrm{CA}$ : Sex differences in geometry of the femoral neck with aging: a structural analysis of bone mineral data. Calcif Tissue Int 50:24-29, 1992

8. Beck TJ, Ruff CB, Bissessur K: Age-related changes in femalc femoral neck geometry: implications for bone strength. Calcif Tissue Int 53(Suppl):S41-S46, 1993

9. Burr DB, Forwood MR, Fyhric DP, Martin RB, Schaffler MB, Turner CH: Bone microdamage and skeletal fragility in osteoporotic and stress fractures. J Bone Miner Res 12:6-15, 1997

10. Burstein AH, Reilly DT, Martens M: Aging of bone tissue: mechanical properties. J Bone Joint Surg [Am] 58:82-86, 1976

11. Carlstrom D: Micro-hardness measurements on single haversian systems in bone. Experientia 10:171-172, 1954

12. Ciarelli MJ, Goldstein SA, Kuhn JL, Cody DD, Brown MB: Evaluation of orthogonal mechanical properties and density of human trabecular bone from the major metaphyseal regions with materials testing and computed tomography. $J$ Orthop Res 9:674-682, 1991

13. Cooper $\mathrm{C}$ : The epidemiology of fragility fractures: is there a role for bone quality? Calcif Tissue int 53(Suppl):S23-S26, 1993

14. Crofts RD, Boyce TM, Bloebaum RD: Aging changes in osteon mineralization in the human femoral neck. Bone 15:147152,1994

15. Currey JD, Brear K: Hardness, Young's modulus and yield stress in mammalian mineralized tissues. I Mat Sci: Mat Med 1:14-20, 1990

16. Currey JD, Brear K, Zioupos P: The effects of ageing and changes in mineral content in degrading the toughness of human femora [published erratum appears in $J$ Biomech 30:1001, 1997]. I Biomech 29:257-260, 1996

17. Dawson-Hughes B, Shipp C, Sadowski L, Dallal G: Bone density of the radius, spine, and hip in relation to percent of ideal body weight in postmenopausal women. Calcif Tissue Int 40:310-314, 1987

18. Doerner MF, Nix WD: A method for interpreting the data from depth-sensing indentation instruments. J Mat Res 1:601609,1986

19. Evans FG: Mechanical properties and histology of cortical bone from younger and older men. Anat Rec 185:1-11, 1976

20. Feik SA, Thomas CD, Clement JG: Age-related changes in cortical porosity of the midshaft of the human femur. $J$ Anat 191:407-416, 1997

21. Goldstein SA, Wilson DL, Sonstegard DA, Matthews LS: The mechanical properties of human tibial trabecular bone as a function of metaphyseal location. J Biomech 16:965-969, 1983

22. Heaney RP: Is there a role for bone quality in fragility fractures? Calcif Tissue Int 53(Suppl 1):S3-S6, 1993

23. Hodgskinson R, Currey JD, Evans GP: Hardness, an indicator of the mechanical competence of cancellous bone. J Orthop Res 7:754-758, 1989

24. Hoffler CE, Guo XE, Zysset PK, Moore KE, Goldstein SA: Evaluation of bone microstructural properties: effect of testing conditions, depth, repetition, time delay and displacement rate. In: Proceedings of the 1997 Bioengineering Conference, Sun River, Oregon, vol BED35, pp 567-568. Ed by KB Chandran, R Vanderby Jr, and MS Hefzy. New York, ASME, 1997

25. Kann P, Schulz U, Klaus D, Piepkorn B, Beyer J: In-vivo investigation of material quality of bone tissue by measuring apparent phalangeal ultrasound transmission velocity. Clin Rheumatol 14:26-34, 1995

26. Kaplan FS, Hayes WC, Keaveny TM, Boskey A, Einhorn TA, Iannotti JP: Form and function of bone. In: Orthopaedic Basic Science, pp 127-184. Ed by SR Simon. Rosemont, Illinois, American Academy of Orthopaedic Surgeons, 1994

27. King RB: Elastic analysis of some punch problems for a layered medium. Int $J$ Solids Structures 23:1657-1664, 1987

28. Ko C-C, Douglas WH, Cheng YS: Intrinsic mechanical competence of cortical and trabecular bone measured by nanoindentation and microindentation probes. In: Proceedings of the 1995 Bioengineering Conference, Beaver Creek, Colorado, vol BED29, pp 415-416. Ed by RM Hochmuth, NA Langrana, and MS Hefzy. New York, ASME, 1995 
29. Lips P: Epidemiology and predictors of fractures associated with osteoporosis. Am J Med 103:3S-8S, 1997

30. McCalden RW, McGeough JA, Barker MB, Court-Brown CM: Age-related changes in the tensile properties of cortical bone: the relative importance of changes in porosity, mineralization, and microstructure. J Bone Joint Surg [AM] 75:11931205,1993

31. McCalden RW, McGeough JA, Court-Brown CM: Agerelated changes in the compressive strength of cancellous bone: the relative importance of changes in density and trabecular architecture. J Bone Joint Surg [Am] 79:421-427, 1997

32. Melick RA, Miller DR: Variations of tensile strength of human cortical bone with age. Clin Sci 30:243-248, 1966

33. Nyssen-Behets C, Duchesne PY, Dhem A: Structural changes with aging in cortical bone of the human tibia. Gerontology 43:316-325, 1997

34. Oliver WC, Pharr GM: An improved technique for determining hardness and elastic modulus using load and displacement sensing indentation experiments. J Mat Res 7:1564-1583, 1992

35. Rho JY, Tsui TY, Pharr GM: Elastic properties of human cortical and trabecular lamellar bone measured by nanoindentation. Biomaterials 18:1325-1330, 1997

36. Roy M, Rho JY, Tsui TY, Pharr GM: Variations of Young's modulus and hardness in human lumbar vertebrae measured by nanoindentation. In: Advances in Bioengineering, vol BED33, pp 385-386. Ed by S Rastegar. New York, ASME, 1996

37. Rubin CT, Lanyon LE: Regulation of bone mass by mechanical strain magnitude. Calcif Tissue Int 37:411-417, 1985

38. Schaffler MB, Choi K, Milgrom C: Aging and matrix micro- damage accumulation in human compact bone. Bone 17:521525,1995

39. Smith CB, Smith DA: Relations between age, mineral density and mechanical properties of human femoral compacta. Acta Orthop Scand 47:496-502, 1976

40. Sneddon IN: The relation between load and penetration in the axisymmetric boussinesq problem for a punch of arbitrary profile. Int J Eng Sci 3:47-57, 1965

41. Vincentelli R: Relation between collagen fiber orientation and age of osteon formation in human tibial compact bone. Acta Anat 100:120-128, 1978

42. Wall JC, Chatterji SK, Jeffery SW: Age-related changes in the density and tensile strength of human femoral cortical bone. Calcif Tissue Int 27:105-108, 1979

43. Weaver JK: The microscopic hardness of bone. $J$ Bone Joint Surg $[$ Am] 48:273-288, 1966

44. Weaver JK, Chalmers J: Cancellous bone: its strength and changes with aging and an evaluation of some methods for measuring its mineral content. I Bone Joint Surg [Am] 48:289298, 1966

45. Wenzel TE, Schaffler MB, Fyhrie DP: In vivo trabecular microcracks in human vertebral bone. Bone 19:89-95, 1996

46. Zysset PK, Goulet RW, Hollister SJ: A global relationship between trabecular bone morphology and homogenized elastic properties. J Biomech Eng 120:640-646, 1998

47. Zysset PK, Guo XE, Hoffler CE, Moore KE, Goldstein SA: Elastic modulus and hardness of human cortical and trabecular lamellae measured by nanoindentation in the human femur. J Biomech 32:1005-1012, 1999 